\title{
What is Food Poverty? A Conceptual Framework
}

by O'Connor, N., Farag, K.W, and Baines, R.N.

Copyright, Publisher and Additional Information:

Author's accepted manuscript published by Emerald in the British Food Journal

DOI: 10.1108/BFJ-06-2015-0222

A note on versions:

The version presented here may differ from the published version or version of record

Harper Adams

University

O'Connor, N., Farag, K and Baines, R. 2016. What is Food Poverty? A Conceptual Framework. British Food Journal, 118 (2), pp.429-449. 


\section{What is Food Poverty? A Conceptual Framework}

\begin{tabular}{|r|l|}
\hline Journal: & British Food Journal \\
\hline Manuscript ID: & Draft \\
\hline Manuscript Type: & General Review \\
\hline Keywords: & food poverty, food security, food policy \\
\hline & \\
\hline
\end{tabular}

SCHOLARONE ${ }^{\text {m }}$

Manuscripts 

What is Food Poverty? A conceptual Framework

$3 \quad 1$ Introduction

4 As an issue which has seen increased recognition in recent years, food poverty 5 within the United Kingdom (UK) has been subject to public, private and 6 governmental interest. Loopstra \& Tarasuk (2013, p.1316) stated that "household 7 food insecurity is increasingly being recognised as a serious public health problem in 8 high income countries". A high level of inflation on essential goods and services, 9 coupled with lower disposable income has increased pressure upon households in 10 achieving an adequate diet. Meanwhile the use of food banks has escalated with all

11 regions affected; consumers have expressed apprehension about food affordability 12 and have petitioned for the issue to be debated in the House of Commons (HC Deb, 13 2013). Businesses and charities such as Kellogg's, Tesco, Oxfam and Red Cross, 14 have identified the problem and responded proactively by engaging in research, 15 providing support and partnering with food distribution schemes. With these 16 concerns in place, the government has instigated investigations through groups such 17 as; the All Party Parliamentary Group (APPG) and the Department for Environment, 18 Food and Rural Affairs (DEFRA).

Dowler \& O Connor (2012) considered food poverty from a rights based perspective, 20 in the role of the government and food systems in the provision and security of 21 adequate food for a nutritionally satisfactory diet. By providing a strong emphasis 22 upon UN agreements for health and nutrition, it was made evident that the 23 government holds responsibility in ensuring that the UK population achieve an equal 24 ability in achieving an adequate diet, particularly in the circumstance where 25 individuals are unable to meet this need. The question of whether this is currently 
26 satisfactory was raised, particularly as national intervention is argued to be less

27 effective than that of local or targeted practices. De Schutter (2009) shared this view

28 stating that "Save in situations of natural disasters or civil strife, the right to food is

29 not the right to be fed; it is the right to feed oneself in dignity'. This has occurred

30 within the UK wherein changes to purchasing behaviour saw households substitute

31 products for lower quality, less nutritious goods which were more calories dense

32 (Griffith, et al., 2013a).

33 The purpose of this study is to improve understanding of food poverty within the UK

34 through a meticulous examination and synthesis of the dimensions of existing

35 literature in order to provide scope for further research. To achieve this, the review

36 initially develops a comprehensive definition of food poverty and then utilises this to

37 investigate UK food poverty within an international context. A discussion of both

38 points provided an overall insight of the issue, wherein a UK specific definition

39 supports examination of the development of food poverty and how it is currently

40 understood. The comparable international exploration of food poverty furthers the

41 definition on a global scale and contextualises the situation in the UK against that of

42 other countries by highlighting similarities and differences.

442 Review Strategy

45 An exploratory approach utilising secondary research was conducted to assemble

46 sufficient information to ensure an extensive examination, consisting of several

47 sources inclusive of academia, government, and non-governmental organisations.

48 The literature was screened for relevance following a broad search which primarily

49 focused upon UK publications, with the exception of national data relevant to 
50 specified countries of USA, Canada, Yemen and United Republic of Tanzania 51 (Tanzania). Key literature included national economic data consisting of the 52 consumer price index $(\mathrm{CPI})$ to represent national inflation of goods and services. 53 Additionally studies conducted on behalf of government such as: Lambie Mumford, 54 et al (2014), APPG (2014) are highly relevant to this topic given the scope of the 55 studies, relevance to the UK and their timeliness, it is also demonstrative of the rising 56 interest in food poverty by the government. Prior to this, much of the available 57 literature was produced independently by charitable organisations (e.g. Trussell 58 Trust and Oxfam), some of these studies have been incorporated despite a lack of 59 subjection to a peer review process, as they were produced by reliable 60 organisations.

61 Timeliness was a crucial factor in the construction of this paper, given the extent of 62 studies conducted in recent years which has increased knowledge of food security 63 and food poverty issues, also given the propensity for change due to economic and 64 national circumstances. As a result of this, $64 \%$ of literatures utilised were published 65 between 2013-2014, with $8 \%$ published prior to 2005 . The parameters of this review 66 were restricted given the breadth of the subject matter, which limited alternative 67 discussion points, including individual knowledge and capabilities, physical access 68 and perceived availability, consumer attitudes, causal linkages with social welfare 69 and sanctions and dietary health needs. These limitations were imposed to enabled 70 a broader discussion of the subject and illustrates the role in which a comprehensive 71 definition can be utilised to encompass the constituents of food poverty. 


\section{Defining Food Poverty}

74 Maslen, et al. (2013) discussed that the definition of UK food poverty developed over

75 time as understanding advanced and yet there remains no consensus for a standard 76 definition, an impediment for the comprehension and conceptualisation of the issue.

77 This disunity is problematic for several reasons including: as an obstacle in 78 academic and political examination, difficulty in ascertaining the quantity or 79 characteristics of individuals classified as such and constraints in addressing related 80 demands.

81 A number of widely utilised definitions were examined to distinguish areas of 82 weakness and compatibility and to enable creation of an appropriate definition. 83 These definitions display similarities between food poverty and food security in the 84 corresponding principles to the pillars of food security: access, availability, utilisation 85 and stability. It is important to note that food insecurity can exist without food poverty 86 as a contributing influence however food poverty cannot exist without food insecurity, 87 as illustrated by figure 1 . Furthermore it is possible for food insecurity to develop as a result of pressures to an individual pillar, while food poverty is driven by a combination of the pillars. The distinction for food poverty can be identified wherein economic access is the predominant component, although it is not the sole 91 characterising element. This is supported by APPG (2014) who identified the key 92 drivers as: unemployment, debt and reliance on social welfare, in addition to other causes such as: access to information and poor skills. Furthermore Coe (2013, p.332) stated that "food poverty does not simply occur due to a lack of money but also develops as a result of a number of other factors, such as a lack of knowledge,

96 skills or equipment to prepare healthy foods". The positioning of food poverty within 97 food insecurity is attributed to the role of the individual pillars wherein economic 
98 access was determined to be the predominant influence and availability of goods the 99 lowest impact.

100

Placement of Figure 1 Relationship between food poverty and food security

102

The relationship between food poverty and food insecurity can be identified through 104 the similarities in definition of these terms. Food security is defined as "...when all 105 people, at all times, have physical and economic access to sufficient, safe and 106 nutritious food to meet their dietary needs and food preferences for an active and 107 healthy life (FAO,1996). This definition was expanded by FAO (2002) to incorporate 108 social access, acknowledging its vital role within the concept. Due to a lack of 109 consensus for a food poverty definition, a range of definitions utilised in the UK were 110 investigated to identify and illustrate the diversity of terminology, definitions identified 111 within Maslen, et al. (2013) were explored, in addition to definitions by authors 112 including; Anderson (1990), Moore (2012) and Food Ethics Council (2013). Food 113 poverty is the inability;

114 "...to afford, or to have access to, food to make up a healthy diet" (Department of 115 Health, 2005, p.7)

116 "...to access a nutritionally adequate diet and the related impacts on health, culture 117 and social participation" (Friel \& Conlon, 2004, p.120)

118 ".. of individuals and households to obtain an adequate and nutritious diet, often 119 because they cannot afford healthy food or there is a lack of shops in their area that 120 are easy to reach" (Food Standards Agency, 2014) 
121 Furthermore while not specific to food poverty, a frequent term utilised to define food

122 poverty is; "Hunger is the inability to acquire or consume an adequate quality or

123 sufficient quantity of food in socially acceptable ways, or the uncertainty that one will

124 be able to do so' (Radimer, et al. 1992).

125 The following common features were identified in the majority of the terminology;

126 economic access, quality, quantity, duration and social dimension. Based upon these

127 elements the proposed concise definition was constructed as; food poverty is the

128 insufficient economic access to an adequate quantity and quality of food to maintain

129 a nutritionally satisfactory and socially acceptable diet.

$130 \quad 3.1$ Components of Food Poverty

$131 \quad 3.1 .1$ Economic access

132 As previously stated, this principle component is essential as income and price 133 determine the ability to procure food and governs the extent to which an individual 134 can achieve the additional elements, to obtain an adequate quantity and quality of 135 food for a nutritious diet, to ensure that this can be achieved immediately and for the 136 foreseeable future and the role of social attributes. Low income consumers place 137 price as a crucial determinant in food expenditure with other influences including 138 demographic, behavioural and lifestyle characteristics (Burns, et al. 2013 and Lee, et 139 al. 2011).

$140 \quad 3.1 .2 \quad$ Adequate quality

141 Food should be nutritionally satisfactory without being inferior in terms of production, 142 manufacturing or preparation. Products targeted at low income consumers can be 143 substandard comparatively, both in nutrition and condition with Dowler \& O Connor 144 (2012) arguing that food poverty had advanced from insufficient economic access to 145 nutritionally poor food choices, as "cheap" food targeted toward low income 
146 consumers can be high in fat, sugar and salt (Dowler, 2008). It has been found that

147 consumers altered expenditure towards products with higher calorie content and fail 148 to meet dietary recommendation, particularly relating to fruit and vegetable 149 consumption (DEFRA, 2013). Price can be an impediment to achieving a healthy 150 diet, however it is conceivable to acquire nutritional sound goods within a lower 151 budget, as demonstrated by Cooper \& Nelson (2003) where six basic products were 152 evaluated and found to have higher nutritional value than premium counterparts.

153

154

155

156

157

158

159

160

161

162

163

\subsubsection{Adequate quantity}

Multiple studies have established that many consumers cut back on food purchases and skipped meals as a result of inadequate income (Cooper \& Dumpleton, 2013 and McHardy, 2013). It is believed that $36 \%$ of retired households cut back on food purchases and 1 in 5 mothers regularly skipped meals to ensure their children could eat (Cooper \& Dumpleton, 2013). Increased cost of food has impacted upon purchasing behaviour where consumers between 2007-2012 purchased $7 \%$ less food, despite a rise in food expenditure of approximately $20 \%$ (Cooper \& Dumpleton, 2013). Regardless of sufficient quality, an adequate volume is required to achieve an appropriate diet.

\subsubsection{Duration}

The classification of Food insecurity as chronic or transitory affects the causes, risks, and solutions and was exemplified through food aid provision where the users of food banks in the UK were identified primarily as experiencing a transitory difficulty, whereby there was a short term, temporary need (Sosenko, et al. 2013). Alternative services such as free school meals and soup kitchens offer continual assistance, providing aid to chronic food insecurity sufferers. The duration and severity of an insufficient diet can impact health as expressed by Martin \& Lippert (2012) who contested that low food security is related to being overweight, whereas very low 
172 food security is related to being underweight. This is concerning given the increase

173 in malnutrition of $19 \%$ between $2013-2014$ and estimates that $25 \%$ of population was

174 obese in 2012 (Faculty of Public Health, 2014 and OECD, 2014).

$175 \quad 3.1 .5$ Social dimension

176 A difference between existing definitions is whether social acceptability is a criterion

177 for inclusion, as several authors excluded the term. It is well established that food

178 serves a purpose beyond nutrition, satisfying emotional, social and cultural needs.

179 Social acceptability is central to food purchasing behaviour as "...the urban food

180 environment shapes and reinforces social stratification" Cannuscio, et al. (2014,

181 pp.18). Burns, et al. (2013) investigated the role of social acceptability within food

182 purchasing behaviour among low income households and found that these decisions

183 were motivated by four goals, to obtain sufficient food to satiate hunger, to acquire

184 desired food products, to gain adequate food when money ran out and to gather food

185 with positive emotional connection. Additionally it was identified that comfort food

186 was purchased regardless of whether sufficient income was available for other

187 expenditure. This is supported by Lee, et al. (2011) who reviewed multiple studies to

188 surmise that additional factors in food purchasing include ethnic background, 189 convenience, habit and body image. Furthermore education and skills can 190 contribute towards risk factors as a higher education level is associated with better 191 diet-while the reduction of at home cooking has negatively impacted the 192 intergenerational transmission of these skills meals (Smith, et al., 2014 and Ricciuto, 193 et al., 2006).

\section{Food Poverty: International Perspectives}

195 Between 2005- 2008, global food prices rose by $83 \%$ with basic agricultural 196 commodity prices such as wheat, rice, corn and soybean achieving record highs 
197 (UN, 2011 and Mittal, 2009). A study conducted by Seale, et al. (2003) of 114 198 countries found that low income countries were approximately twice as responsive to 199 changes to food prices as middle or high income countries. Nord, et al. (2014) stated 200 that an increase in the relative price of food compared to CPI of $1 \%$ was associated 201 with $0.6 \%$ increase in prevalence of food insecurity. Organisation for Economic Co202 operation and Development (OECD) countries were found to experience significantly 203 lower inflation, with a peak of $7 \%$ in 2008 , compared with $23 \%$ in Africa (Economist, 204 2014). This is illustrated by the range of volatility experienced by the countries 205 examined, with the exception of the USA where data was unavailable, as shown in 206 table 1. Conversely, volatility in the UK exceeded that of Tanzania at several 207 conjectures, demonstrating the extent of volatility which impacted the UK.

Placement of Table 1 Annual domestic food price volatility index (FAO, 2014a)

Net food consumers in developing countries spend a large percentage of 212 expenditure on food, estimated between $60-80 \%$, contrasted with $10-20 \%$ in wealthy 213 countries (UNCTAD, 2008). Within urban areas in developing countries, there are 214 fewer food producers ${ }_{2}$ and households are reliant upon market systems to access 215 food, leaving them susceptible to the price volatility (Tacoli, et al., 2013 and Mittal, 216 2009).

217 As a result of the food price spike, poverty rates measured as US\$1p/day increased 218 by $4.5 \%$ in low income countries (Ivanic \& Martin, 2008). This is supported by Wodon 219 \& Zaman (2009) who found that higher prevalence of poverty in Sub Saharan Africa 220 was attributable to the negative effect of inflation on consumer purchasing power. 
221 Internationally it is estimated that 68million additional individuals fell below the

222 poverty line as a direct consequence of rising food prices in 2007-08 (World Bank, 223 2011). In 2012, 28.2\% of Tanzania were classified as below the national poverty 224 line, with $43.5 \%$ had an income lower than $\$ 1.25$ a day and $73 \%$ below $\$ 2$ per day 225 (World bank, 2014), The food price spike of 2007-08 increased poverty levels in 226 Yemen by $44 \%$, with $45 \%$ of the population below the poverty line (UNICEF \& WFP, 227 2014). Extreme poverty is less prevalent in developed countries, given higher levels 228 of household income; however relative poverty remained comparatively stable. In $2292013,14.5 \%$ of American and $11.9 \%$ of Canadian population were classified as 230 experiencing relative poverty, in comparison to $15 \%$ of the UK population $\mathrm{BHC}$ 231 (DeNavas-Walt \& Proctor, 2014 and OECD, 2014).

232 An inability to afford food increases susceptibility to health risks due to an 233 inadequate diet, such as malnutrition, nutrition deficiencies and stunting (Tacoli, et 234 al., 2013 and UN, 2011). Internationally 805million individuals were estimated to be 235 chronically undernourished in 2012-2014, the majority of whom are resident in 236 developing countries, approximately 790.7 million individuals, the remaining 15 237 million individuals are in developed countries (Food and Agriculture Organisation 238 (FAO), 2014b). Despite food insecurity pressures overall the volume of individuals 239 reported as malnourished internationally has reduced from $18.7 \%$ in $1990 / 92$ to $240 \quad 11.3 \%$ in $2012 / 14$.

241 Economic accessibility of food is vital to national security and insufficient access can 242 result in extreme reactions, as demonstrated by the food price riots of 2007-2008 243 where many countries experienced civil unrest and violent protests (Berazneva \& 244 Lee, 2013). there were a number of underpinning circumstances which contributed 245 towards the food riots of 2007-08, which were explored by Berazneva \& Lee (2013), 
246 whereby causal linkages were found between the likelihood to particpate in food riots

247 and economic, demographic and political elements related to poverty, urbanization,

248 oppressive political structures, and higher civil liberties in addition to coastal location 249 and food availability and access.

\subsection{Case Studies: Developing Countries}

251 Tanzania was ranked as 159 of 187 countries in 2014 UNDP human development 252 index, due to the extent of poverty and deprivation, with $19 \%$ of the population living 253 below the food poverty line in 2007 and $43 \%$ of households not consuming enough 254 calories in 2010-11 World Food Programme (WFP) (2013). Comparatively, Yemen 255 was graded as 154 but was the $8^{\text {th }}$ most food insecure country in the world (Von 256 Grebmer, et al., 2014) with 10.6 million individuals, $41 \%$ of the population food 257 insecure in 2014 (UNICEF \& WFP, 2014). Attributable to food security risks relating 258 to socioeconomic problems aggravated by 07-08 price spike and 2011 politic crisis, 259 in addition to resource depletion and environmental threats (UNICEF \& WFP, 2014). 260 While the causes of food insecurity in Tanzania are inclusive of drought, high food 261 and oil prices, insufficient infrastructure, seasonal shortages and lack of dietary 262 diversity. Both countries recorded high levels of chronic and acute health concerns 263 relating to malnutrition, stunting and dietary deficiencies, in Yemen, 46.6\% of 264 children were stunted or chronically malnourished (SOFI, 2014), with just 12.4\% 265 meeting WHO's dietary diversity recommendations (UNICEF \& WFP, 2014). In 266 Tanzania 34.6\% of children were malnourished between 2012-2014 (FAO, 2014b).

267 Food price inflation is above that of average inflation rates, and significantly higher 268 than that in developed countries. Given that a higher percentage of expenditure in 269 these areas is attributable to food purchases, any increase in prices can create 270 reduction in affordability. High inflation contributed towards diminished food security 
271 in both countries, with food prices in Tanzania volatile and consistently above

272 inflation rates with both countries experiencing a significant increase, although

273 political unrest in Yemen contributed to the sharp incline in 2011, as shown in figures

$274 \quad 2$ and 3.

275

276

Placement of Figure 2 CPI in Tanzania, 2010= 100. (derived from National Bureau of Statistics, 2014)

277

278

279

Placement of Figure $3 \mathrm{CPI}$ in Yemen, 2008=100. (derived from Central Statistical Organisation, 2014;

Central Statistical Organisation, 2010)

280

281

It is evident that both countries were subject to poor government coping strategies,

282

and as such were reliant on external aid. More than half the population of Yemen,

14.7million individuals relied on humanitarian assistance in 2014 according to the

284 Yemen humanitarian response plan, with approximately 6million individuals reached

285 through WFP's main programme (UNICEF \& WFP, 2014). Less physical food aid is

286 provided to Tanzania where WFP supplies food approximately 1.6 million individuals

287 through programmes such as food for education, food for assets and maternal and

288 child health programme. These countries have been experiencing severe food

289 security risks, of which food poverty, driven by reduced purchasing power and

290 inflation is one of many contributing elements.

\subsection{Case Studies: Developed Countries}

292 In Canada, food insecurity has been consistently monitored and has shown a steady

293 increase from 2005. In 2012, approximately 13\%, 4 million individuals were food

294 insecure (Tarasuk, et al., 2014). Similarly in America, food insecurity was found to

295 rise substantially between 2008- 2013, from 36.2 million in 2007 to 49.1 million

296 (approximately 15\%), with 6.8million recorded as in very low food insecurity 
297 (Coleman-Jensen, et al., 2014). However Weinfield, et al. (2014) argued that 298 17.6million were food insecure, which highlights the disparity in preferred 299 measurement systems.

300 Coping strategies for food shortages were similar between these countries, and differ 301 dependant on duration, with the most utilised options including delaying bills, rent 302 and selling possessions (Weinfield, et al., 2014 and Loopstra \& Tarasuk, 2013b). In 303 America, it was found that $96 \%$ of respondents substituted products, while $88 \%$ 304 reduced the volume used, while $79 \%$ purchased unhealthy inexpensive food, $40 \%$ 305 watered down food and drink (Feeding America, 2012). Whereas in food insecure 306 households in Canada, 98.1\% stated they had reduced portion size or skipped 307 meals, 83.1\% relied on low cost food for children's meals (Tarasuk, et al., 2014).

Additionally there are charitable and governmental services which provide aid to food insecure households. Federally assisted programmes in America have an uptake of 310 approximately $60 \%$ amongst food insecure households of at least one programme. 311 In spite of this in 2012, $27 \%$ of the food insecure were ineligible for federal 312 assistance as household income was above the required criteria (Weinfield, et al., 313 2014). Due to this, there is reliance upon alternate food assistance, of which there is 314 an extensive system that is partially supported by Feeding America, who provide 315 food for an estimated 46.5million individuals per year, equating to approximately $31662 \%$ of national food aid distribution (Weinfield, et al., 2014). Comparatively a survey 317 of 4,743 food banks in Canada were found to assist 833,098 individuals in March 318 2013, an increase of 23\% from March 2008 (Food Banks Canada, 2013), although 319 just $1 / 4$ of food insecure Canadians are believed to avail of this, due to preference or 320 inaccessibility. With food banks usually providing 5 days were of food to each 321 individual, this is suggestive that approximately $3,500,000$ meals were distributed. 
322 Additionally it was recorded that 4,341,659 meals were provided by other services 323 such as soup kitchens, breakfast clubs and shelters (Food Banks Canada, 2013).

324 Volatile food prices contributed to reduced purchasing power, food prices exceeded 325 the average rate of inflation. Figures 4 and 5 show the difference in CPI for Canada and USA, where the initial peak in food prices was experienced first by USA, both

327 countries saw a significant drop the subsequent years as reactive measures were 328 enacted.

329

Placement of Figure 4 CPI Canada, 2002=100. (derived from Statistics Canada, 2014)

Placement of Figure 5 CPI USA, 2005=100. (derived from Crawford \& Church, 2014)

\section{Food Poverty: UK}

335 From a historical perspective, in the UK gross disposable household income (GDHI) 336 was relatively high in 2013 yet in real terms from 2009, income had reduced to levels 337 of 2002-03 (Office of National Statistics (ONS), 2014a and Levy, 2013). Equivalised 338 income levels developed at different rates for socio economic groups, and in the 339 period 2007/08-2012/13 the greatest reduction in income was experienced by the top 340 quintile (5.2\% reduction of $£ 3300)$; comparatively the bottom quintile experienced an 341 increase of $3.5 \%$ ( $£ 400$ ) (ONS, 2014a). There is an unequal distribution of income 342 between locations, as demonstrated by GDHI per person in 2012 in table 2 where 343 London the highest levels were recorded in London at $27.7 \%$ above the national 344 average, whereas the lowest income was found in Northern Ireland at $17.2 \%$ below 345 (ONS, 2014b). 
Placement of Table 2 GDHI per head 2012, (data from ONS, 2014b)

Lee, et al. (2014) found that much of UK poverty is centralised to cities and that areas with relatively low poverty rates, retain "concentrations of deprivation", which illustrates location based inequality. From 2008, individuals who had been suffering 352 from poverty have experienced greater levels of deprivation, while more people have become increasingly vulnerable due to economic stagnation, increased living costs and public service reductions (Oxfam, 2012 and Joseph Rowntree Foundation, 2013a). Following 2007; households have also been subjected to benefit cuts, lower disposable income and unemployment, furthering financial pressures (Coe, 2013).

In 2012, 13 million people were estimated to be in relative poverty after housing costs (figure 6 ) with $21 \%$ of the population were estimated to be in relative poverty in 2012/13 (Department Work and Pensions (DWP), 2012). Comparatively before housing costs, relative poverty was recorded at a lower level (6\% lower in 2012/13), indicating that this fixed cost can increase vulnerability to poverty.

In a study of multiple deprivation ONS (2013) identified that approximately $1 / 3$ of the population were unable to cope with unexpected financial expenses, however 367 Gordon, et al. (2013) stated that almost half the UK population are experiencing 368 financial insecurity, with 18million people unable to afford adequate housing 369 conditions and 4 million improperly fed. There was a $10 \%$ increase in the percentage 
370 of the country unable to cope with unexpected financial costs from 2007-11 which

371 demonstrates a rise in households inability to adapt to shocks (table 3 ).

372

373

374

375

376

377

378

379

380

381

382

383

384

385

386

387

388

389

390

391

392

393

394

Placement of Table 3 Percentage of population unable to afford specific items 05-11. (data from DWP, 2012)

Increased inflation can exacerbate pressure on household budgets and CPI annual rate of inflation shows volatility within the previous decade, with peaks in 2008 and 2011, comparable to international trends. Inflation was inconsistent across expenditure categories (figure 7) where overall between 2007-2014, CPI increased by $21.5 \%$ while food $(35.9 \%)$, alcohol $(43.9 \%)$ and housing \& fuel $(34.1 \%)$ all demonstrated significantly higher increases in price.

\section{Placement of Figure 7 Difference in CPI 2007-2014. (data from ONS, 2014a)}

It is important to note that food inflation regularly exceeded CPI for all items (figure 8) and that food prices in 2014 remained at similar levels to the previous year which contrasted to the volatility shown in the earlier stages. Within this category, all items increased in price from $28 \%$ for milk, egg and cheese to $47.8 \%$ for oils and fats, as shown in figure 9. Inflation affected all food goods and occurred at separate points during the 2007-2014 period. The greatest annual increase in price occurred in 2008, with highs of $17.2 \%$ for oils and fats and $15.1 \%$ for milk, egg and cheese.

Placement of Figure 8 CPI UK, 2006=100. (data from ONS, 2014a) 
Placement of Figure 9 Growth in CPI inflation 2007-14. (data from ONS, 2014a)

397

398 Food accounts for $17.5 \%$ of total household expenditure on average, succeeded by 399 fuel and housing. Increased inflation of this category affects available funding for other expenditure categories (Griffith, et al., 2013a). Low income households are particularly susceptible to food price increases as argued by Lang \& Schoen (2014), 402 Revoredo-Giha, et al., (2009) and Downing, et al., (2014). A study of consumer 403 perception found that increased cost, particularly of food was a particular concern to consumers with $37 \%$ of respondents stating that they were finding it difficult to afford the variety of food they wanted, a figure which increased to $50 \%$ for households with 406 income below $£ 14000$ (Dowler, et al., 2011)

One change in consumer purchasing behaviour has been product substitution, reflected in the growth of discount retailers such as Aldi and Lidl, where consumers have elected to move from national brands towards cheaper products. Consumer studies have found that as a result of "economic stagnation", consumer behaviour has altered, with lower levels of brand loyalty, with greater focus upon price (Lamey, 2014). As discount retailers offer a means to reduce food expenditure, they have experienced growth as a result. Reduced purchasing power is linked to the growth of 414 both hard and soft discount retailers (Lamey, 2014). Grocery discount retailers grew 415 by $33.4 \%$ between 2008 and 2011 with $6.2 \%$ of grocery sales in 2014 , with this trend 416 predicted to continue with sales estimations of $10.9 \%$ in 2019 while supermarket own 417 label products have grown by $9.3 \%$ annually (Institute of Grocery Distribution (IGD), 4182014 \& Keynote, 2013). This behaviour change illustrates that people are changing 419 where they shop, away from where they would normally go, driven partially by price. 


\section{Discussion}

421 Through an examination of existing literatures on the subject, food poverty has been

422 defined as the insufficient economic access to an adequate quantity and quality of 423 food to maintain a nutritionally satisfactory, socially acceptable diet. This brief, 424 comprehensive term encompasses five elements which are popularly utilised within 425 the current knowledge of the issue, yet differentiates itself in several ways. First this 426 definition was developed specific for UK application with an awareness of the 427 influential role of household finance in meeting dietary requirements. Secondly, 428 simple terminology was employed to enable multi level use and understanding. 429 Thirdly, the role of a social dimension is recognised as a pertinent factor to individual 430 requirements given the influence of factors such as education, skills, culture, 431 preferences, and emotional relationship with products.

432 Definitions which discuss food poverty have been widely utilised in the UK, however 433 it is argued that these established definitions are insufficient to describe food 434 poverty. Faults in established definitions include misrepresentation wherein quotes 435 have been taken out of context (Radimer, et al., 1992), overly generalised, where the 436 term is descriptive of food security rather than focussed upon food poverty 437 (Anderson, 1990) and incomplete terminology, in that all contributing factors to food 438 poverty have not been included (Department of Health, 2005).

\section{$439 \quad$ 6.1 UK Food Poverty}

440 Food prices in the UK were found to increase higher and persist longer than other

441 OECD countries and this prolonged experience increased the cumulative effect upon 442 individuals, worsening their circumstances (Griffith, et al., 2013a). Purchasing power 443 reduced due to a decline in real income and increased inflation, for example median 444 real income for parents with dependent children fell $7.5 \%$ between $2007-2011$ 
445 (Griffith, et al., 2013a). Food, as a relatively flexible expense allows consumers to 446 reduce expenditure on this category. Griffith, et al. (2013b) explored the difference in 447 consumer purchasing behaviour between 2005-07 and 2010-12 and found that all 448 households reduced real expenditure on food and on average, households reduced 449 real expenditure on food (into the home) by $8.5 \%$ and reduced purchased calories by $4503.6 \%$, equating to a lower expenditure per calorie of $5.2 \%$. However Coe (2013) 451 found that the lowest income households spent $17 \%$ more on food between $2007-11$, 452 and received $3.2 \%$ less products.

453 The increased pressure upon households has increased reliance upon food 454 assistance, as demonstrated with the growth of Trussell Trust which showed growth 455 of $32,350 \%$ between $2005-06$ to $2013-14$, with 913,138 people utilising the service in 456 2013-14 (figure 10). There have been several publications relating to food parcel 457 distribution; Lambie-Mumford, et al. (2014), Maslen, et al. (2013), Downing, et al. 458 (2014) and Lyall, (2014), which found a growing demand for food assistance 459 throughout the country however data on demand for other services is unavailable, 460 and figures for food bank usage is reliant upon Trussell Trust data although there are 461 multiple food assistance resources available which have yet to be examined. While 462 this information may be indicative of national growth experienced by food parcel 463 providers, Sosenko, et al. (2013) identified that Trussell Trust was not necessarily 464 the dominant provider of food aid in all areas. Comparatively, it was believed that 465 Trussell Trust provided approximately two thirds of food parcels for Dundee and $46620 \%$ in Glasgow (Sosenko, et al., 2013). 


\subsection{UK and International Comparison}

472 A fundamental dissimilarity expressed by Nord (2009) that starvation is a rare occurrence in developed countries, with a more likely outcome to be a reduction in quality and quantity of food amongst low-middle income households. Dowler \& $\mathrm{O}$ Connor (2012) supported this belief, stating that as a result of diminished affordability the frequency of food consumption and the nutritional quality of food had reduced.

477 Evidenced by the prevalence of malnourishment and nutrient deficiency in developing countries and obesity and over nutrition in developed countries.

479 Darmon \& Drewnowski (2008) found a correlation in developed countries between 480 income and obesity and micronutritient deficiency, with the causal mechanisms between diet quality and low income consumers consisting of food prices \& diet costs, food access, education \& culture while Ricciuto, et al. (2006) and Smith, et al. (2014) found that knowledge, skills, time and available funds contribute towards individuals diets, with low income consumers purchasing less raw ingredients such as fruit and vegetables, in favour of ready to eat and calorie dense products.

The development of inflation within the case study countries examined, table 4 shows that inflation was significantly higher and more volatile in developing countries, yet the UK regularly exceed inflation for the other developed countries, consistent with food price volatility.

Placement of Table $4 \mathrm{CPI}$ annual percentage change. (Data from Crawford \& Church, 2014; Statistics Canada, 2014; Central Statistical Organisation, 2014; Central Statistical Organisation, 2010 and World Bank, 2014b)

493 Reliance upon food aid was found to increase in developed countries, however at a 494 lower growth rate than the UK, while physical food aid towards developing countries 
495 has fallen. Reliance upon food banks in developed countries is significant with 496 millions of meals distributed each year. Despite established measures available to 497 address this demand, the level of support following the reduction in food affordability 498 failed to completely meet the needs of individuals, in most developed or developing 499 countries.

500 The volume of users has been monitored for these services in many countries, a 501 matter which has not been possible within the UK, as there is currently no cohesive 502 body to track this development. Similarly, food poverty has been explored in depth 503 within the case study countries, providing a foundation upon which to compare the 504 UK situation however further research is required in the uk to ascertain nationally 505 specific understanding. This is emplefied by the countries examined who held 506 measurement toolkits to determine the quantity of indivuals classified as food 507 insecure or as food impoverished, such methods have not been undertaken within 508 the uk.

509 Other food insecurity risks which occur concurrently increase the risk of food poverty, 510 as seen in developing areas, yet within the UK, the affordability of food is the 511 predominant concern. The cumulative impact of food poverty can reduce resilience 512 and prolong the negative consequences for individuals.

\section{Conclusion}

514 Food poverty is not a new problem as a result of food price spikes of $2007 / 08$, as

515 evidenced by a history of food aid. However increases in food and energy prices 516 reduced food affordability for almost all socio economic groups around the world with 517 the lowest income households impacted most severely. As an area with numerous 
518 gaps in research, there is broad scope for further study to fully understand the extent 519 of the situation both internationally and within the UK.

520 An identification of the components of food poverty through an examination of the 521 existing terminology enables the creation of a definition which encompasses all 522 contributing factors. The advantage in ascertaining this information is to promote 523 unity in discussion and examination by all interested stakeholders, where previously 524 discord and misunderstanding impeded discussion and examination of the subject. 525 Establishing a definition facilitated examination of the UK and international 526 environment, in addition to empowering further research and minimising current gaps 527 in knowledge.

528 Comparative to the countries examined, the UK has significant gaps in 529 understanding inclusive of; numbers and classification of individuals experiencing or 530 vulnerable to food poverty, causes and symptoms of food poverty, methods of 531 alleviation, short and long term consequences associated with transitory and chronic 532 food poverty, impact upon consumer behaviour and coping strategies employed. 533 These are areas which have been analysed in other regions with recognisable 534 parallels; however there are limited academic studies which are UK specific. Utilising 535 available knowledge from areas with substantial expertise, these issues are 536 recommended for further research, to improve understanding of the subject relevant 537 to the UK.

538 Despite indications that UK food poverty is an escalating problem, due to limited 539 measurement studies, this cannot be presented with certainty, as such the creation 540 and application of measurement indicators would be beneficial to quantify individuals 541 classified as in food poverty. Furthermore, there is a general lack of knowledge 
542 regarding identification of vulnerable individuals particularly amongst minority 543 groups, and whether any correlation exists with influences such as; ethnicity, religion 544 and education. In addition to ascertaining the severity of this problem, it would 545 improve the ability to target vulnerable individuals.

546 As a subject which has been acknowledged as a significant concern to society, it 547 would be advantageous to determine the extent of national food poverty, both in the 548 short term (to identify and meet the needs of vulnerable individuals) and in the long 549 term (to determine the long term impacts of the present problem and to forecast 550 likely trends). By investigating food poverty from a broad focus, it was found that this 551 was not exclusive to the UK, and as an ongoing challenge it appears to be 552 escalating, both nationally and internationally. 


\section{References}

555

556 Anderson, S. A. (1990) Core Indicators of Nutritional State for Difficult-to-Sample

557 Populations, Journal of Nutrition, Nov 1990, vol.120, pp. 1559-1600

558

559

All Party Parliamentary Group on Hunger and Food Poverty (APPG) ( 2014) Feeding

560 Britain; A Strategy for Zero Hunger in England, Wales, Scotland and Northern

561 Ireland, the Children's Society, London, 8.12.2014

562

563 Berazneva, J. \& Lee, D.R. (2013) Explaining the African Food Riots of 2007-2008:

564 An Empirical Analysis, Food Policy, vol. 39, pp. 28-39

565

566

Cannuscio, C.C., Hillier, A., Karpyn, A. \& Glanz, K. (2014) The Social Dynamics of

Healthy Food Shopping and Store Choice in an Urban Environment, Social Science

568

and Medicine, Vol. 122, pp. 13-20

569

570

Central Statistical Organisation (2014) Statistical Yearbook 2013, 22.07.2014,

available at: http://www.cso-yemen.org/

572

573 Central Statistical Organisation (2010) Statistical Yearbook 2009, 13.06.2010,

available at: http://www.cso-yemen.org/

575

Coe, S. (2013) Feeding the Family, Are Food Prices Having an Effect, British

Nutrition Foundation, Nutrition Bulletin, vol. 38, pp 332-336

Coleman-Jensen, A., Gregory, C., \& Singh, A. (2014) Household Food Security in 580 the United States in 2013, EFF-173, US Department of Agriculture, Economic

581 Research Service, Washington, Sept 2014

582

Cooper, N. \& Dumpleton, S. (2013) Walking the Breadline; the Scandal of Food 
587 Cooper, S. \& Nelson, M. (2003) Economy Line Foods From Four Supermarkets and 588 Brand Name Equivalents; a Comparison of their Nutrient Contents and Costs, 589 Journal of Human Nutrition and Dietetics, vol. 16, no. 5, pp.339-347 590

591 Crawford, M. \& Church, J. (2014) CPI Detailed Report, US Bureau of Labour 592 Statistics, Washington, Aug 2014

593

594

Darmon, N. \& Drewnowski, A. (2008) Does Social Class Predict Diet Quality?

595 American Journal of Clinical Nutrition, Vol. 87, pp.1107-1117

596

597

DEFRA (2013) Family Food 2012, Family Food Statistics, DEFRA, London,

598 12.12.2013

599

600

Department of Health (2005) Choosing a Better Diet: A Food and Health Action Plan, 601 NHS, London, 09.03.2005

602

Department of Work \& Pensions (DWP) (2012) Households Below Average Income. 604 An Analysis of the Income Distribution 1994/95 - 2010/11, London, June 2012 605

606 DeNavas-Walt, C. \& Proctor, B.D. (2014) Income and Poverty in the United States:

607 2013, US Census Bureau, Current Population Reports, Washington, Sept 2014 608

De Schutter, O. (2009) The Right to Food and the Political Economy of Hunger, 610 Twenty-sixth McDougall Memorial Lecture, Opening of the 36th Session of the FAO 611 Conference

613 Dowler, E (2008) Policy Initiatives to Address Low-Income Households' Nutritional 614 Needs in the UK, Proceedings of the Nutrition Society, vol. 67, pp. 289-300

615 Dowler, E, Kneafsey, M, Lambie-Mumford, H., Inman, A., Collier, R (2011) Thinking 616 About Food Security, Engaging With UK Consumers. Critical Public Health, Vol. 21, 617 No. 4, pp. $403-416$ 
619 Dowler, E. \& O'Connor, D (2012) Rights Based Approaches to Addressing Food

620 Poverty and Food Insecurity in Ireland and UK, Social Science and Medicine, Vol.

62174, pp. 44-51

622

623 Downing, E., Kennedy, S. \& Fell, M. (2014) Food Banks and Food Poverty, House of

624 Commons Briefing Paper, London, 09.04.2014

625

626

FAO (2014a) Food Security Indicators; Domestic Food Price Volatility, 17.11.2014,

627 available at: www.fao.org

628

629 FAO (2014b) The State of Food Insecurity in the World, FAO, IFAD \& WFP, Rome,

$630 \quad 16.09 .2014$

631 FAO (2002) The State of Food Insecurity in the World 2001. Rome

632 FAO (1996) Rome Declaration on World Food Security and World Food Summit Plan

633 of Action, World Food Summit, 13-17 November 1996, Rome

634 Feeding America (2012) In Short Supply; American Families Struggle to Afford

635 Everyday Essentials, Chicago, available at:www.feedingamerica.org

636

637 Food Banks Canada (2013) Hunger Count, Food Banks Canada, Toronto

638

639 Friel, S. \& Conlon, C. (2004) Food Poverty and Policy Ireland: Combat Poverty

640 Agency, Dublin, April 2004

641

642 Food Standards Agency (2014) Food Poverty, available at: www.food.gov.uk

643

644 Griffith, R., O'Connell, M. \& Smith, K. (2013a) Food Expenditure and Nutritional

645 Quality over the Great Recession, IFS Briefing Note BN143, ESRC, Nov 2013

646

647 Griffith, R., Lluberas, R. \& Lührmann, M. (2013b) Gluttony in the UK? Long-Term

648 Change in Diet, IFS Briefing Note BN142, Nov 2013

649 
650 Gordon, D., Mack, J., Lansley, S., Main, G., Nandy, S., Patsios, D. \& Pomati, M.

651 (2013) The Impoverishment of the UK, Poverty and Social Exclusion, ESRC,

$652 \quad 28.03 .2013$

653

654 House of Commons Hansard Debates, 18.11.2013, col. 806

655

656

Institute of Grocery Distribution (IGD) (2014) UK Grocery Market to be Worth £203bn

657

by $2019,30.06 .2014$

658

659 Ivanic, M. \& Martin, W. (2008) Implications of Higher Global Food Prices for Poverty

660 in Low-Income Countries. World Bank Policy Research Working Paper, No. 4594

661 Washington, World Bank. April 2008

662

663

Keynote (2013) Discount Retailing Market Update 2013, available at:

664

www.keynote.co.uk

665

666

Lamey, L. (2014),"Hard Economic Times: A Dream for Discounters", European

667 Journal of Marketing, Vol. 48, no. 3/4 pp. 641-656

668

669

670

Lang, T. \& Schoen, V. (2014) UK Food Prices, Cooling or Bubbling. Food Research

671

672 Lee, J H, Ralston, R.A. \& Truby, H (2011) Influence of food Cost on Diet Quality and

673 Risk Factor for Chronic Disease: A Systematic Review. Nutrition and Dietetics, vol.

674 68, pp. 248-261

675

676 Lee, N., Sissons, P., Hughes, C., Green, A., Atfield, G., Adam, D. \& Rodriguez-Pose,

677 A. (2014) Cities, Growth and Poverty; A Review of Evidence. Joseph Rowntree

678 Foundation, Feb 2014

679

680 Loopstra, R .\& Tarasuk, V. (2013) Severity of Household Food Insecurity is Sensitive 681 to Change in Household Income and Employment Status Among Low Income

682 Families, American Society for Nutrition, Journal of Nutrition, vol. 113, 12.06.2013 683 
684 Martin, M. A. \&Lippert, A (2012) Feeding her Children, but Risking her Health: The 685 Intersection of Gender, Household Food Insecurity and Obesity, Social Science and 686 Medicine, vol. 74 , no. 11, pp. 1754-1764

687

Maslen, C., Raffle, A., Marriot, S and Smith, N (2013) Food Poverty, What Does the

Evidence Tell Us, Appendix, Bristol City Council, July 2013

690

691

McHardy, F. (2013) Surviving Poverty, The Impact of Loan Parenthood, Research

692 into Impacts of Poverty on Lone Parents in Rural Fife, Poverty Alliance

693

Mittal, A (2009) The 2008 Food Price Crisis: Rethinking Food Security Policies, G-24

Discussion Paper Series, UNCTAD, No. 56, June 2009

696

Moore, R (2012) Definitions of Fuel Poverty, Implications for Policy, Energy Policy,

Vol. 49 , pp. $19-26$

699

700

National Bureau of Statistics (2014) Annual Average Inflation Rates for the Past Five

Years from 2009 - 2013, Dar es Salaam, Tanzania, 08.01.2014

702

703

Nord, M., Coleman-Jensen, A. \& Gregory, C. (2014) Prevalence of U.S. Food

704

Insecurity is Related to Changes in Unemployment, Inflation, and the Price of Food,

USDA, Economic Research Report Number 167, Washington, June 2014

706

707

Nord, M (2009).Food Spending Declined and Food Insecurity Increased for Middle-

708

Income and Low-Income Households from 2000-2007, Economic Information

709

Bulletin, No. 61, United States Department of Agriculture, Economic Research

710 Service, Washington, Oct 2009

711

712

OECD (2014) Obesity And The Economics Of Prevention: Fit Not Fat, Key Facts -

England, Update 2014, 27.05.2014, available at: www.oecd.org

ONS (2014a) Consumer Price Indices - CPI indices: 1988 to 2014, Dataset, tables/data-selector $\cdot$ html?cdid=D7BT\&dataset=mm23\&table-id=1.1 
719 ONS (2014b) Regional Gross Disposable Household Income 2012, ONS, London,

721

722

ONS (2013) Poverty and Social Exclusion in the UK and EU 2005-11, ONS, London, 723 16.01.2013

724

Radimer, K. L., Olson, C. M., Green, J. C., Campbell, C. C. \& Habicht, J. P. (1992).

Understanding Hunger and Developing Indicators to Assess it in Women and

Children, Journal of Nutrition Education, Vol.24, no.1, pp. 36-44

728

729

Revoredo-Giha, C., Leat, P., Kupiec-Teahan, B., Lamprinopoulou, C. \& Cacciolatti,

Ricciuto, L., Tarasuk, V. \& Yatchew, A. (2006) Socio-demographic Influences on

Food Purchasing Among Canadian Households, European Journal of Clinical

735 Nutrition, vol. 60, pp. 778-790

736

737

Seale, J., Regmi, A. \& Bernstein, J. (2003) International Evidence on Food

738

Consumption Patterns, Technical Bulletin 1904, Washington, United States

Department of Agriculture

Smith, L.P, Ng, S.W. \& Popkin, B.M (2014) Resistant to the Recession: Low-Income

Adults' Maintenance of Cooking and Away-From-Home Eating Behaviors During

Times of Economic Turbulence, American Journal of Public Health, Vol. 104, no. 5, 744 pp. $840-846$

745

Sosenko, F., Livingstone, N. \& Fitzpatrick, S. (2013) Overview of Food Aid Provision

in Scotland, Edinburgh, Scottish Government

748

Statistics Canada, (2014) Consumer Price Index, Table 326-0021, available at: 
752 Tacoli, C., Bukhari, B., \& Fisher, S. (2013) Urban Poverty, Food Security and

753 Climate Change, Human Settlements Working Paper No.37, Rural-Urban

754 Interactions and Livelihood Strategies, International Institute for Environment and

755 Development, March 2013

756

757

Tarasuk, V., Mitchell, A. \& Dachner, N, (2014) Household Food Insecurity in Canada

758 2012, Research to Identify Policy Options to Reduce Food Insecurity (PROOF),

759 Toronto

760

761

UNICEF \& WFP (2014) Comprehensive Food Security Survey, WFP, Yemen,

November 2014

763

764

Von Grebmer, K., Saltzman, A., Birol, E., Yohannes, Y., Menon, P., Thompson, J.,

Wiesmann, D., Prasai, N., Yin, S. and Sonntag, A. (2014) Global Hunger Index, The

Challenge of Hidden Hunger, IFPRI, 30.10.2014

767

Weinfield, N., Mills, G., Borger, C., Gearing, M., Macaluso, T., Montaquila, J. \&

Zedlewski, S. (2014) Feeding America, Hunger in America 2014, National Report,

Washington, August 2014

771

772

Wodon, Q. \& Zaman, H. (2009) Higher Food Prices in Sub-Saharan Africa: Poverty

773

Impact and Policy Responses. World Bank Research Observer Vol.25 no.1, pp.157-

World Bank (2014), World Development Indicators, Poverty Headcount Ratio, available at: www.data.worldbank.org

World Bank (2014b) World Development Indicators, Inflation; Consumer Prices,

available at: www.data.worldbank.org

World Bank (2008) Global Food Prices for Poverty in Low-Income Countries, World 
786 World Bank (2011) Food Price Watch, World Bank Washington, February 2011 787

788 WFP (2013) Comprehensive Food Security and Vulnerability Analysis, Tanzania 789 2012, WFP, Sep 2013

790 


\section{Figures}

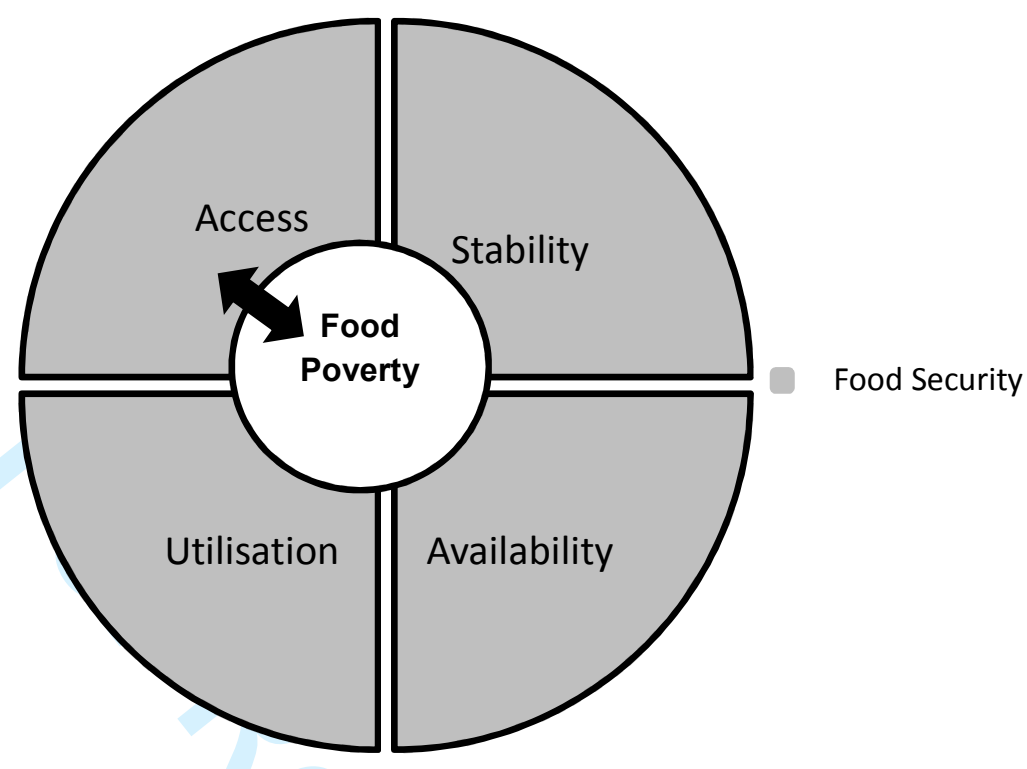

Figure 1 Relationship between food poverty and food security 


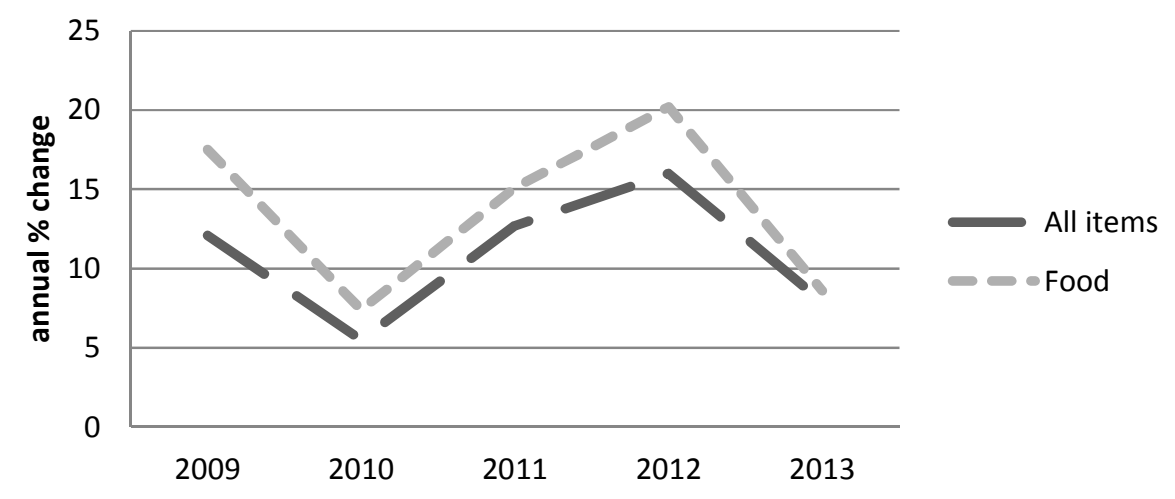

Figure 2 CPI in Tanzania, 2010= 100. (derived from National Bureau of Statistics, 2014) 


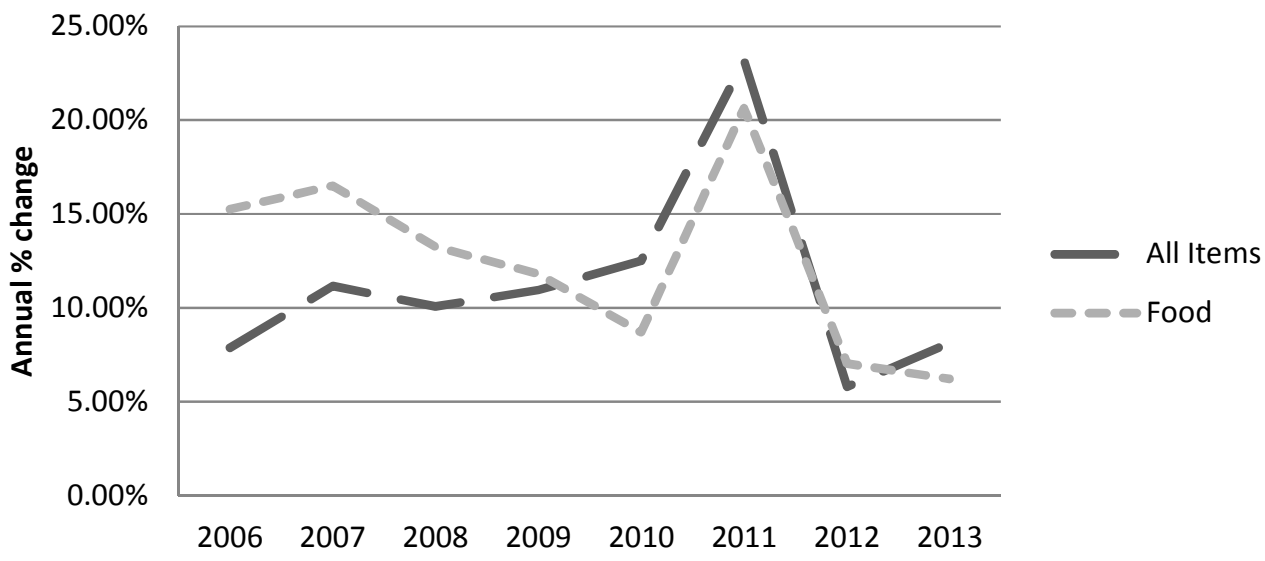

Figure $3 \mathrm{CPI}$ in Yemen, 2008=100. (derived from Central Statistical Organisation, 2014; Central Statistical Organisation, 2010) 
1

2

3

4

5

6

7

8

9

10

11

12

13

14

15

16

17

18

19

20

21

22

23

24

25

26

27

28

29

30

31

32

33

34

35

36

37

38

39

40

41

42

43

44

45

46

47

48

49

50

51

52

53

54

55

56

57

58

59

60

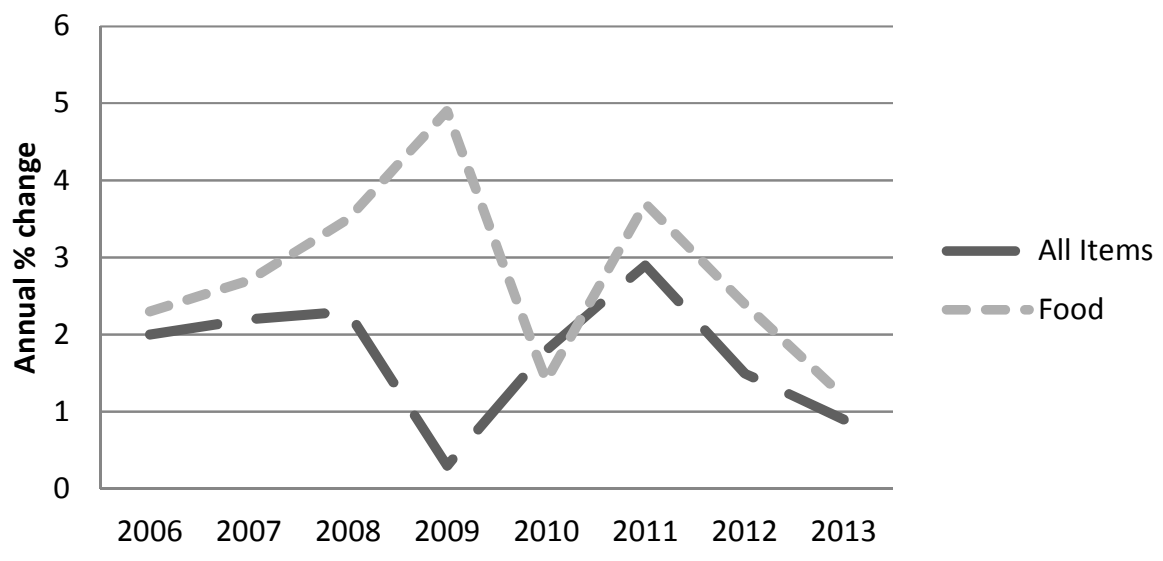

Figure 4 CPI Canada, 2002=100. (derived from Statistics Canada, 2014) 


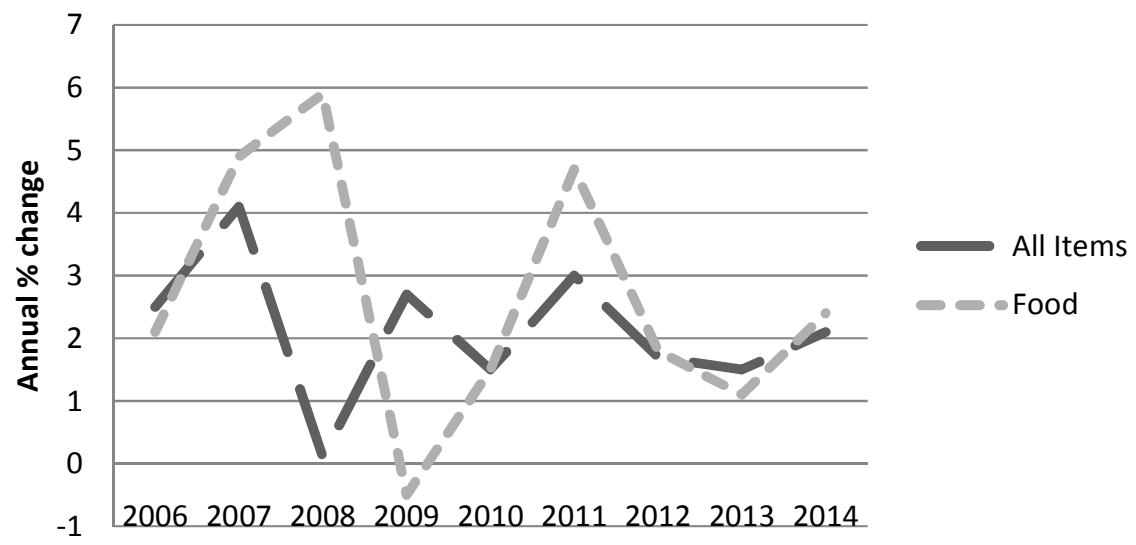

Figure 5 CPI USA, 2005=100. (derived from Crawford \& Church, 2014) 
1

2

3

4

5

6

7

8

9

10

11

12

13

14

15

16

17

18

19

20

21

22

23

24

25

26

27

28

29

30

31

32

33

34

35

36

37

38

39

40

41

42

43

44

45

46

47

48

49

50

51

52

53

54

55

56

57

58

59

60

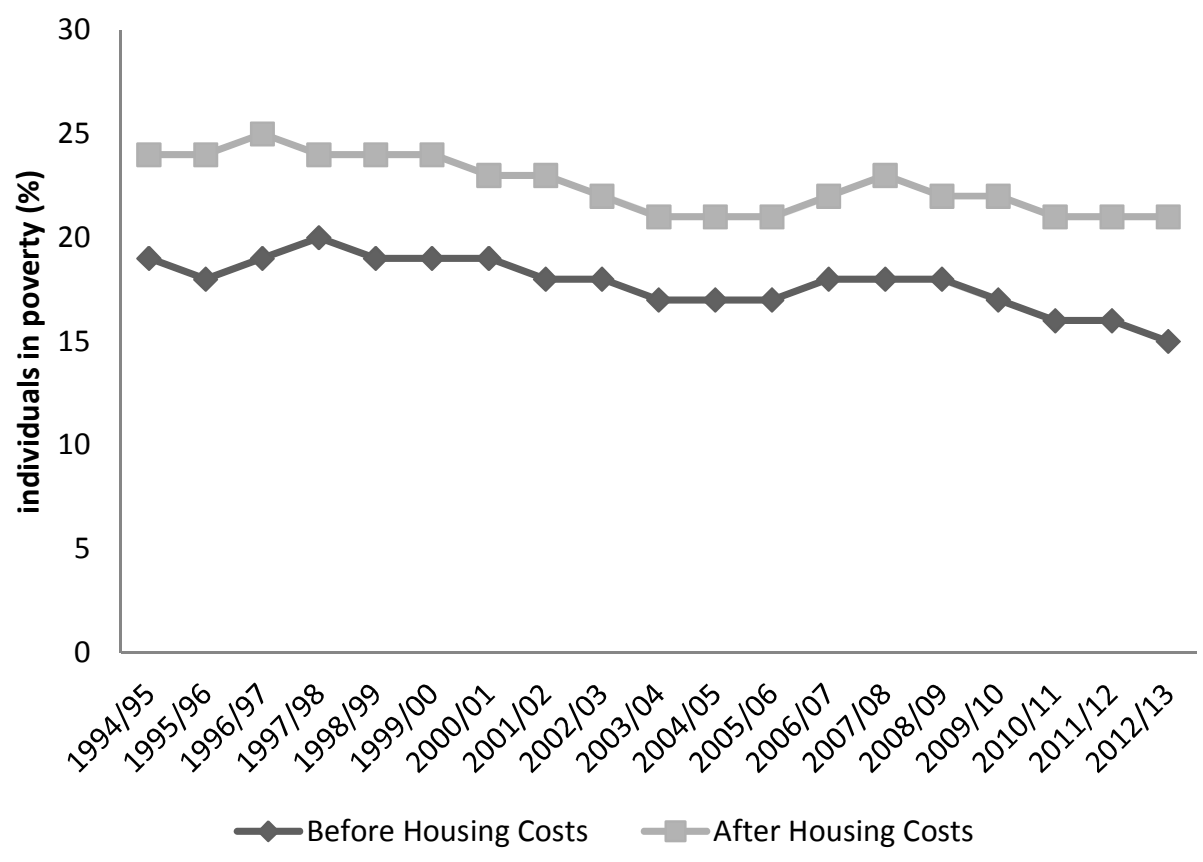

Figure 6 Percentage of individuals in relative poverty. (data from ONS, 2014) 


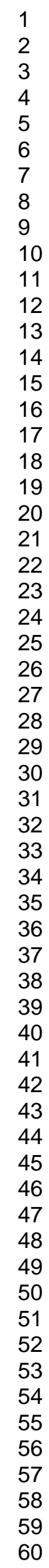

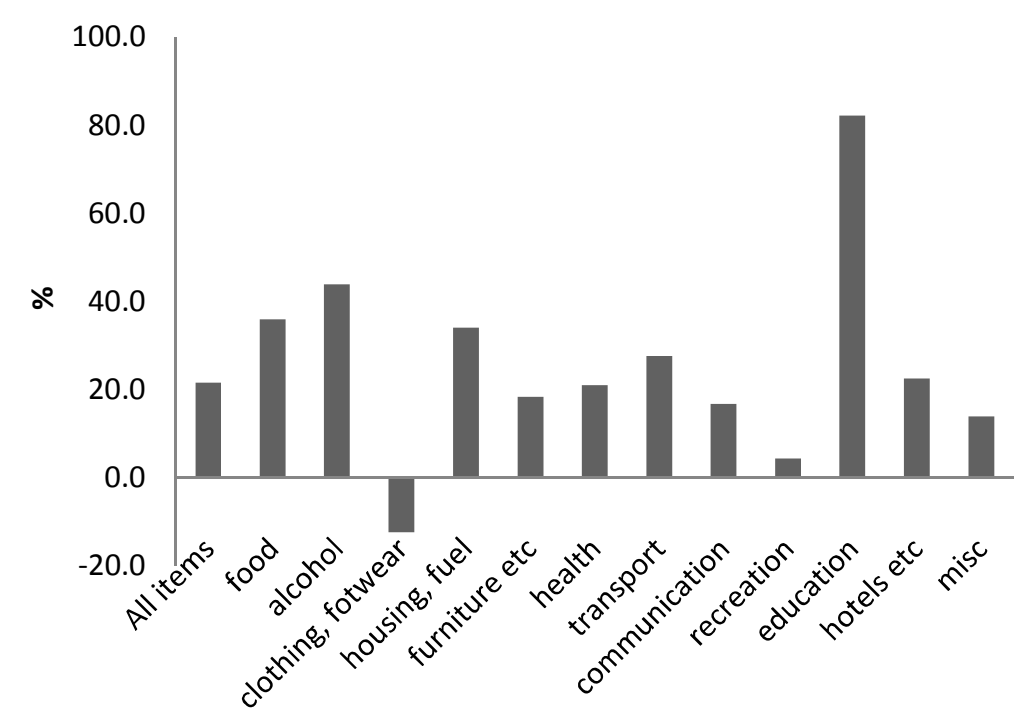

Figure 7 Difference in CPI 2007-2014. (data from ONS, 2014a) 
Page 39 of 45

British Food Journal

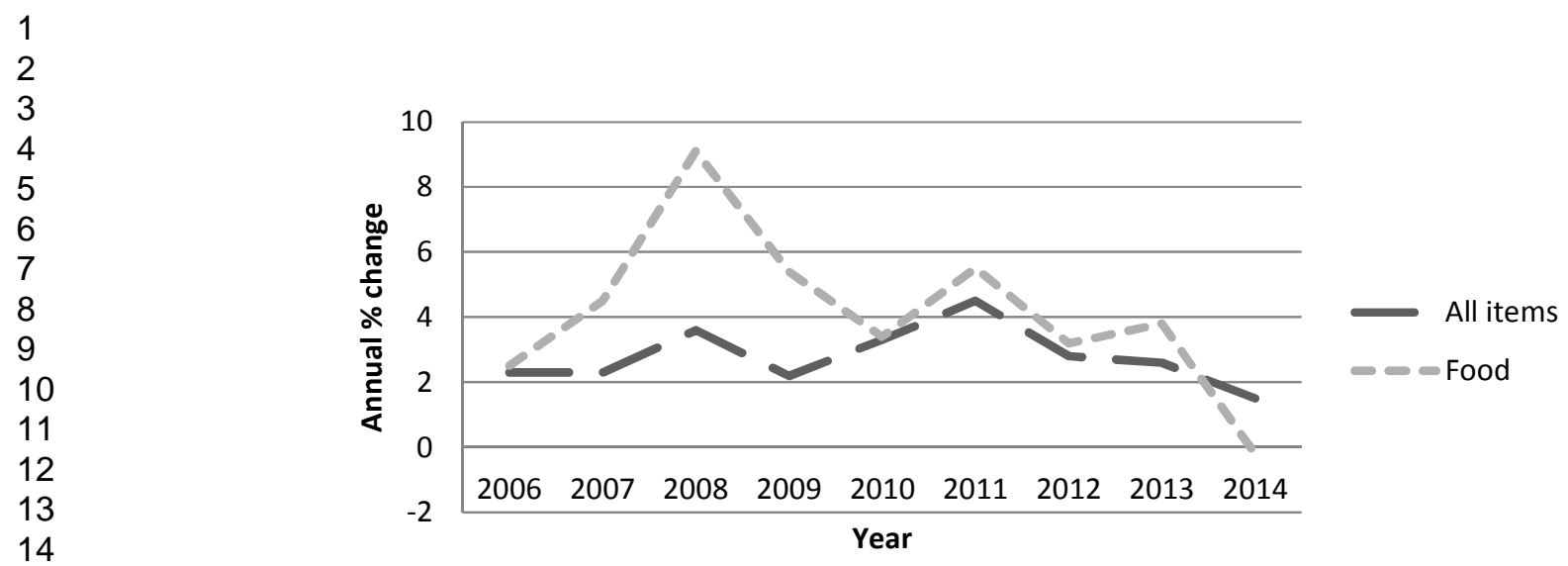

Figure 8 CPI UK, 2006=100. (data from ONS, 2014a) 


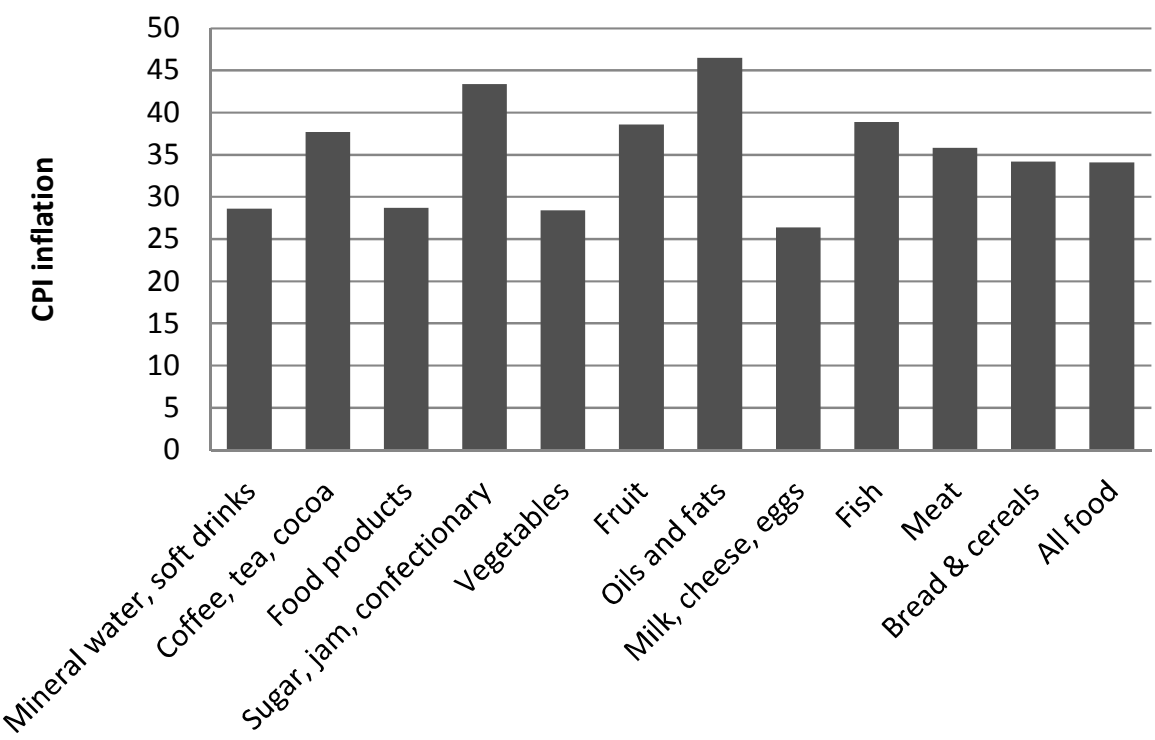

— change 2007-2014

Figure 9 Growth in CPI inflation 2007-14. (data from ONS, 2014a) 


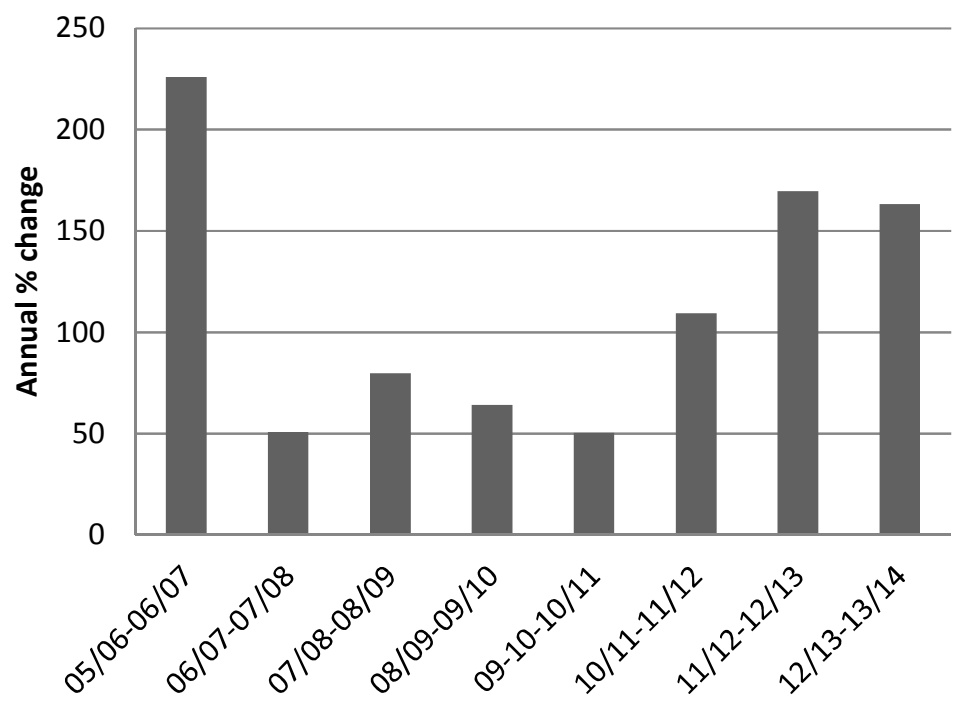

Figure 10 Percentage growth in Trussell Trust reliance. (data from Trussell Trust, 2014) 
1 Table 1 Annual domestic food price volatility index (FAO, 2014a)

\begin{tabular}{llllllllll}
\hline & $\mathbf{2 0 0 6}$ & $\mathbf{2 0 0 7}$ & $\mathbf{2 0 0 8}$ & $\mathbf{2 0 0 9}$ & $\mathbf{2 0 1 0}$ & $\mathbf{2 0 1 1}$ & $\mathbf{2 0 1 2}$ & $\mathbf{2 0 1 3}$ & $\mathbf{2 0 1 4}$ \\
\hline $\begin{array}{l}\text { United Republic of } \\
\text { Tanzania }\end{array}$ & 10.1 & 10.9 & 8.0 & 8.5 & 12.0 & 4.9 & 4.9 & 7.0 & 4.8 \\
Yemen & & & & & & & & & \\
Canada & 35.0 & 22.1 & 33.2 & 9.7 & 13.9 & 12.0 & 15.3 & 11.0 & \\
United Kingdom & 3.8 & 4.9 & 4.8 & 4.9 & 4.7 & 5.4 & 5.2 & 5.9 & 7.8 \\
\hline
\end{tabular}

2 
4 Table 2 GDHI per head 2012, (data from ONS, 2014b)

\begin{tabular}{lr}
\hline Regions & $\begin{array}{r}\text { GDHI per head } \\
(£)\end{array}$ \\
\hline North East & 14,393 \\
North West & 14,939 \\
Yorkshire and The Humber & 14,575 \\
East Midlands & 15,206 \\
West Midlands & 14,744 \\
East of England & 17,630 \\
London & 21,446 \\
South East & 19,126 \\
South West & 16,914 \\
United Kingdom & 16,791 \\
\hline
\end{tabular}


7 Table 3 Percentage of population unable to afford specific items 05-11. (data from DWP, 2012)

\begin{tabular}{|c|c|c|c|c|c|c|c|}
\hline Item & 2005 & 2006 & 2007 & 2008 & 2009 & 2010 & 2011 \\
\hline Unexpected financial expenses & 31 & 28.8 & 26.6 & 28.6 & 31.1 & 34.6 & 36.6 \\
\hline One week's annual holiday & 23.3 & 22.9 & 21.4 & 24.2 & 26.1 & 27.3 & 29.7 \\
\hline $\begin{array}{l}\text { Mortgage or rent payments, utility } \\
\text { bills or loan payments }\end{array}$ & 6.7 & 8.7 & 8.5 & 7 & 8.05 & 9.1 & 8.9 \\
\hline $\begin{array}{l}\text { Heating to keep home adequately } \\
\text { warm }\end{array}$ & 5.8 & 4.7 & 4.6 & 6 & 5.8 & 6.1 & 6.5 \\
\hline A car & 5.3 & 5 & 4.9 & 5.1 & 4.9 & 6 & 6.3 \\
\hline Eat meat or protein regularly & 6.1 & 4.5 & 3.9 & 4.3 & 4.1 & 5 & 4.9 \\
\hline
\end{tabular}

8

9 
10 Table 4 CPI annual percentage change. (Data from Crawford \& Church, 2014; Statistics Canada, 2014;

11 Central Statistical Organisation, 2014; Central Statistical Organisation, 2010 and World Bank, 2014b)

\begin{tabular}{lllllllll}
\hline & $\mathbf{2 0 0 6}$ & $\mathbf{2 0 0 7}$ & $\mathbf{2 0 0 8}$ & $\mathbf{2 0 0 9}$ & $\mathbf{2 0 1 0}$ & $\mathbf{2 0 1 1}$ & $\mathbf{2 0 1 2}$ & $\mathbf{2 0 1 3}$ \\
\hline $\begin{array}{l}\text { United Republic of } \\
\text { Tanzania }\end{array}$ & 7.3 & 7.0 & 10.3 & 12.1 & 6.2 & 12.7 & 16.0 & 7.9 \\
Yemen & & & & & & & & \\
Canada & 7.9 & 11.2 & 10.1 & 11.0 & 12.5 & 23.2 & 5.8 & 8.1 \\
USA & 2.0 & 2.2 & 2.3 & 0.3 & 1.8 & 2.9 & 1.5 & 0.9 \\
United Kingdom & 2.5 & 4.1 & 0.1 & 2.7 & 1.5 & 3.0 & 1.7 & 1.5 \\
& 2.3 & 2.3 & 3.6 & 2.2 & 3.3 & 4.5 & 2.8 & 2.6 \\
\hline
\end{tabular}

12

13 